$\checkmark$ Research Square

\title{
Clinical significance and prognostic role of tumor- associated macrophages infiltration according to histologic location in canine mammary carcinomas
}

Lidianne Narducci Monteiro

UFMG

Diego Carlos dos Reis

UFMG

Breno Souza Salgado

UFES

Geovanni Cassali ( $\square$ geovanni.cassali@gmail.com )

UFMG https://orcid.org/0000-0002-5650-6743

\section{Research Article}

Keywords: macrophages, inflammation, tumor microenvironment, mammary tumors, dog

Posted Date: October 28th, 2019

DOI: https://doi.org/10.21203/rs.2.16195/v1

License: (c) (i) This work is licensed under a Creative Commons Attribution 4.0 International License. Read Full License

Version of Record: A version of this preprint was published at Research in Veterinary Science on March 1st, 2021. See the published version at https://doi.org/10.1016/j.rvsc.2020.10.010. 


\section{Abstract}

Background: Tumor-associated macrophages (TAMs) have been involved in growth and metastases of human and canine mammary tumors. However, the prognostic importance of TAM specific location in canine mammary tumors (CMT) was not evaluated. In this study we evaluated the potential role of TAMs in specific histologic locations intratumoral (ITAM) and stromal (sTAM), as well as total macrophage (TTAM) counts - as prognostic indicators in CMT.

Results: Clinico-pathologic data from 66 animals with mammary carcinoma and their tumors were used in this study. Samples were stained with anti-macrophage antibody for subsequent TAM count. High levels of TTAM, STAM, and tTAM were related with clinical stage and vascular invasion. Additionally, TTAM alone revealed a relation with tumor size, while high levels of sTAM and TTAM also were correlated with node metastasis and a poor prognosis based on survival analysis.

Conclusions: CMT with aggressive features can reveal higher TAM counts. TAMs are associated with vascular invasion and nodal metastasis, and STAM and TTAM counts are correlated with overall survival, consequently leading to the conclusion that sTAM and/or TTAM counts could be used as prognostic indicators in canine mammary invasive carcinomas.

\section{Background}

Mammary cancer is frequent in female dogs and represents a major issue in veterinary medicine since many animals die due to tumor dissemination. Previous studies have addressed infiltration by leukocytes in canine mammary tumors' microenvironment and evaluated mostly lymphocyte [1] and macrophage [2-4] populations and highly infiltrated tumors revealed a poor prognosis.

Macrophages represent a major component in the tumor microenvironment. They infiltrate tumor tissues and are thought to be related with tumor progression in human [5-10] and canine cancers [2-4]. Although the original hypotheses proposed that macrophages were involved in antitumor immunity, there is substantial clinical and experimental evidence that in most of cases these cells enhance tumor evolution to malignancy [11-13]. They are called tumor-associated macrophages (TAMs) and have been associated with angiogenesis and tissue remodeling whitin tumors, this helping in the metastatic process $[6,12-14]$. High infiltration of macrophages has been recently correlated with poor prognosis in both human [7-8] and canine [2-4] patients with mammary tumors.

However, the prognostic importance of TAM specific location in such tumors was not evaluated to date. Accordingly, the aim of this study was to evaluate the significance of TAM infiltration in different histologic compartiments (intratumoral vs. stromal vs. total) in invasive canine mammary carcinomas and its relation with tumors' clinicopathologic features.

\section{Materials And Methods}

\section{Patients, samples, and follow-up}

This study was approved by the Ethics Committee on Animal Use of the Federal University of Minas Gerais, Brazil (protocol \#81-2013). Sixty-six female dogs diagnosed with mammary carcinomas from 2011 to 2015 were used in this study. All patients were submitted to surgical mastectomy as treatment option with subsequent microscopic 
evaluation of the removed mammary tumors. They were classified according to the World Health Organization's histologic criteria for canine mammary tumors diagnosis [16] and to updated classification propositions [17]. Subsequently, tumors were graded using the Nottingham grading system [18]. When dogs presented more than one malignant neoplasm, the tumor with the more aggressive clinical and histopathologic features (e.g., larger size, undifferentiated histology) was selected, as recommended by other authors [19]. The WHO's staging system [20] was used for determination of clinical stage based on animals' clinical, radiographic, and sonographic findings.

Patients' data were obtained by phone interviews with owners and by reviewing the clinical data available at the Institution's Veterinary Teaching Hospital regarding animals that died at the place. Overall survival (OS) was calculated and characterized as the time from surgery/tumor removal to the date of animal death/euthanasia due to tumor-related causes and/or end of the study. When the owners did not answer the or when animals died from other causes data was censored.

\section{Immunohistochemical staining}

For immunohistochemistry, 3um-thick sections were obtained from paraffin blocks and mounted on poly-L-lysinecoated slides. Sections were deparaffinized and rehydrated and subsequently submitted to heat-induced epitope/antigen retrieval for 30 seconds at $125^{\circ} \mathrm{C}$ using the Trilogy antigen retrieval buffer (Cell Marque Corporation, Rocklin, CA) in a pressure chamber (Pascal Pressure Chamber, Dako, Carpinteria, CA). Proteinase $\mathrm{K}$ antigen retrieval was used when suitable, with subsequent incubation of tissue sections with a mouse anti-macrophage antibody (clone MAC387, 1:400, AbD Serotec, Oxford, UK). Canine lymph node tissue was used as positive control for reactions while negative controls were obtained by using isotype-matched primary antibodies. For anti-macrophage immunohistochemistry, the staining was revealed by using a polymer based detection system (Envision G2 System/AP, rabbit/mouse, Dako) with liquid permanent red as chromogen (Permanent red substrate-chromogen, Dako) and visualized under light microscopy.

\section{Immunolabelling and quantification of tumor-associated macrophages}

Immunoreaction was considered as positive for anti-macrophage antibody when cytoplasmic diffuse or granular staining (but no nuclear) was observed and simultaneously demonstrating macrophage morphology. Since the antibody also stains granulocytic cells, macrophages were distinguished from other cells, such as neutrophils by nuclear morphologic, a non-segmented nucleus. The number of stained TAMs were counted in each tumor in five hot spot areas first detected at low magnification and then captured at x200 magnification (total area of $1 \mathrm{~mm}^{2}$ ) without any previous knowledge of patients' clinical data. TAM hot spots were chosen rather than random fields, because these areas are thought to be biologically the most important [21-22]. For cutoff point analysis, the medians were used to categorize tumors into high and low TAM groups.

In order to distinguish intratumoral (i.e., intratumoral) and stromal TAM, criteria previously applied by other authors [10] and based on differentiation of stromal from intratumoral lymphocytes [23-24] were used. Intratumoral TAM was defined as macrophages within tumor cell nests an in direct contact with tumor cells, and stromal TAM were characterized as macrophages infiltrating tumor stroma (Figure 1). After counting, the number of intratumoral, 
stromal, and total TAM (sum of both types) was calculated. Median values were calculated for each histologic location and used for categorization of tumors as with low or high TAM infiltration.

\section{Statistical analysis}

TAM infiltration was compared using analysis of variance (ANOVA) with TAM value as a continuous variable. Correlation between the number of macrophages and clinicopathologic features was assessed using Spearman rank order correlation or the Mann-Whitney U test, which was used for comparison between different histologic locations. Survival curves were produced using the Kaplan-Meier method and differences in survival time between patients were evaluated using the log-rank test. Results were considered as statistically significant when $P \leq 0.05$.

\section{Results}

\section{Clinical and histologic data}

The mean age of the subjects was twelve years (range, four to twenty years). After histopathologic evaluation, tumors were classified as carcinomas in mixed tumors (26 cases/39.39\%), papillary carcinomas (11 cases/16.66\%), solid carcinomas (10 cases/15.15\%), micropapillary carcinomas (7 cases/10.60\%), and tubular carcinomas and carcinosarcomas ( 6 cases each/9.09\% each). From all tumors, 13 cases (19.69\%) were high grade (grade 3), whereas $20(30.30 \%)$ and 33 cases (50\%) were of grades 1 and 2, respectively. Twenty-two samples (33.33\%) presented with vascular invasion, 29 (43.93\%) cases revealed evidence of nodal metastasis, and 2 cases presented with distant metastasis (3.03\%). Clinicopathologic data are summarized in Table 1.

\section{Macrophage count and clinicopathologic features}

Macrophages showed moderate to intense cytoplasmic staining and were observed as single or clustered cells forming densely packed groups. The distribution of TAMs in CMT was rather heterogeneous and frequently observed at the stroma of the tumor front (Figure 1), around necrotic areas of the tumor, associated with areas of cartilage and bone production in mixed tumors (not shown), and within tumor nests (intratumoral) (Figure 1). All tumor histotypes revealed macrophage positivity, and there were tumors which revealed no iTAM or sTAM infiltration. The highest tTAM count was of $1282 / \mathrm{mm}^{2}\left(1219 \mathrm{sTAM} / \mathrm{mm}^{2} ; 63 \mathrm{iTAM} / \mathrm{mm}^{2}\right)$ in a papillary carcinoma counts. Median TAM counts $/ \mathrm{mm}^{2}$ were used as cuttof values for ITAM, sTAM, and tTAM in order to categorize them as of low or high TAM infiltration (iTAM: $\leq 61.5,>61.5$; sTAM: $\leq 57.5,>57.5$; tTAM: low $\leq 149,>149$, Figure 2A-B).

All TAM counts (iTAM, sTAM, and tTAM) revealed a correlation with clinical stage $(P=0.0380,0.0162$, and 0.0004 , respectively; Table 1$)$ and vascular invasion $(P=0.0235,0.0371$, and 0.0371 , respectively; Table 1$)$. The tTAM count also correlated with tumor size $(P=0.0017$; Table 1$)$, while sTAM and tTAM revealed a relation with lymph node metastasis $(P=0.0256$; Table 1$)$. No significantly statistical association was observed between TAM counts and ulceration, necrosis, histologic grade, or distant metastasis.

\section{Survival analysis and TAM counts}

To assess the prognostic significance of TAM infiltration, patients were first classified according to iTAM, sTAM, and tTAM counts. Survival data were available for the 66 animals. A significant relationship between TAM infiltration and overall survival was revealed for tTAM $(P=0.0282$; Figure 3A) and STAM $(P=0.0500$; Figure 3B), but not for iTAM $(P$ 
$=0.8439$; Figure 3C). Median overall survival of dogs with mammary tumors with high TAM counts was of 950 days

(Table 2). The curve did reach the median survival time in cases with low sTAM and tTAM at 613 days.

\section{Discussion}

Mammary tumors are the most common neoplasms in non-spayed adult female dogs [16-17]. Since they can be extremely aggressive and lead to death of animals and because of the large number of cellular events involved in cell growth, differentiation, proliferation, invasion and metastasis, the investigation of TAMs may be a great relevance for the understanding of CMT progression. Therefore, in this study we addressed the role of TAMs in CMT progression and the importance of those cells in specific locations in such tumors. In humans, there is strong evidence of TAMs association with neoplastic progression and metastasis in different tumor types [11], including breast cancer [7-10]. This feature was also recently described in dogs with mammary cancer $[2,3,12]$.

TAMs have a diverse role according to their microenviroment and histologic location [5, 7-9], but still little information is available for dogs, with lack of data regarding the specific location of such cells within tumors. In this study, high levels of TAM infiltration were associated with aggressive clinicopathologic features in canine mammary carcinomas. Additionally, stromal and total TAM counts were related with lymph node metastasis and with a poor prognosis given their influence on overall survival, in a similar way to what is observed in women [7-10]. Despite the well known role of various leukocytes in tumor microenvironment functional state, this feature was not unexpected because macrophages are highly motile and can cross between tissues microlocalizations freely.

In previous studies, necrosis and skin ulceration have also been suggested to be indicators of higher tumor aggressiveness in dogs [25], but were not significantly associated with TAM counts in this study. The absence of a significant association between TAMs and necrotic tissue or ulceration could be explained by the method used to count macrophages, in which counting was focused in hot spots whithin tumor stroma and tumor nests

(intratumoral area). However, a relation between a higher TAM counts (ITAM, sTAM, and tTAM) and clinical stage and vascular invasion was found - while tTAM was also related with tumor size - similarly to what was observed by other authors $[3,26]$. Additionally, sTAM and tTAM were found to be associated with lymph node metastasis - an expected feature given the hability of macrophages in remodeling tumor stroma and acting as a major player in the enhancement of tumor cell migration and invasion [27]. These features are highly important for metastasis, reinforcing the role of macrophages in canine mammary carcinoma progression. Despite this, we did not observe a relation between TAM counts and histologic grade, in concordance with other authors' reports [2, 3, 25]. This finding could indicate that macrophage infiltration can be associated with another tumor features independent from its histologic grade.

In this study, higher sTAM and TTAM counts were also correlated with survival and prognosis, in concordance with other authors results [2]. The relation between the evaluated clinicopathologic data and higher TAM counts indicate a relation with a worse prognosis and survival rate, similarly to what is observed in women with breast cancer $[10,21]$ consequently highlighting the potential role of TAMs as prognostic indicators in canine invasive mammary carcinomas.

\section{Conclusions}

In summary, it is possible to conclude that CMT with aggressive features can reveal higher TAM counts. TAMs are associated with vascular invasion and nodal metastasis, and STAM and TTAM counts are correlated with overall 
survival, consequently leading to the conclusion that sTAM and/or TTAM counts could be used as prognostic indicators in canine mammary invasive carcinomas.

\section{Abbreviations}

CMT - Canine mammary tumors OS - Overall survival TAMs - Tumor-associated macrophages

\section{Declarations}

\section{Conflict of interest statement}

The authors declare that there is no conflict of interest regarding the publication of this article.

\section{Acknowledgements}

We wish to thank the Minas Gerais State Research Foundation (FAPEMIG-research grant APQ-01951-15), the Coordination for the Improvement of Higher Education Personnel (CAPES-PhD grant), and the National Council for Scientific and Technological Development (CNPq-research grant 477386/2014-2) of Brazil for the financial support. We also wish to thank Dr. Renée Amorim for the anti-macrophage antibody and Tatiany Silveira and Fernanda Nunes for their help with technical issues.

\section{Authors' contributions}

All authors participated to the study design and planning. LM, DdR and BS performed the experiments. LM, BS and GD analyzed the data. LM, DdR, BS and GD wrote the paper.

\section{References}

1. Estrela-Lima A, Araújo MSS, Costa-Neto JM, Teixeira-Carvalho A, Barrouin-Melo SM, Cardoso SV, et al. Immunophenotypic features of tumor infiltrating lymphocytes from mammary carcinomas in female dogs associated with prognostic factors and survival rates. BMC Cancer. 2010;10:1-14. doi: 10.1186/1471-2407-10256.

2. Raposo T, Gregório H, Pires I, Prada J, Queiroga FL. Prognostic value of tumour-associated macrophages in canine mammary tumours. Veterinary and Comparative Oncology. 2014;12:10-19. doi: 10.1111/j.14765829.2012.00326.x

3. Raposo T, Pires I, Carvalho MI, Prada J, Argyle DJ, Queiroga FL. Tumour-associated macrophages are associated with vascular endothelial growth factor expression in canine mammary tumours. Veterinary Comparative Oncology. 2015;13:464-474. doi: 10.1111/vco.12067.

4. Monteiro LN, Rodrigues MA, Gomes DA, Salgado BS, Cassali GD. Tumour-associated macrophages: Relation with progression and invasiveness, and assessment of M1/M2 macrophages in canine mammary tumours. Veterinary Journal. 2018;234:119-125.doi: 10.1016/j.tvjl.2018.02.016.

5. Ohno S, Inagawa H, Soma G, Nagasue N. Role of tumor-associated macrophage in malignant tumors: should the location of the infiltrated macrophages be taken in account during evaluation? Anticancer Research.

2002;22:4269-4275. 
6. Solinas G, Germano G, Mantovani A., Allavena P. Tumor-associated macrophages (TAM) as major players of the cancer-related inflammation. Journal of Leukocyte Biology. 2009;86:1065-1073. doi: 10.1189/jlb.0609385.

7. Mahmoud SMA, Lee AHS, Paish EC, Macmillan RD, Ellis IO, Green AR. Tumour infiltrating macrophages and clinical outcomes in breast cancer. Journal of Clinical Pathology. 2012;65:159-163. doi: 10.1136/jclinpath-2011200355.

8. Medrek C, Ponten F, Jirstom K, Leandersson K. The presence of tumor associated macrophages in tumor stroma as a prognostic marker for breast cancer patients. BMC Cancer. 2012;12:306. doi: 10.1186/1471-2407-12-306.

9. Ch'ng ES, Tuan Sharif SE, Jaafar H. In human invasive breast ductal carcinoma, tumor stromal macrophages and tumor nest macrophages have distinct relationships with clinicopathological parameters and tumor angiogenesis. Virchow Archive. 2013;462:257-267. doi: 10.1007/s00428-012-1362-4.

10. Gwak JM, Jang MH, Kim DI, Seo AN, Park SY. Prognostic value of tumor-associated macrophages according to histologic location and hormone receptor status in breast cancer. PLoS ONE. 2015;10:1-14. doi: 10.1371/journal.pone.0125728

11. Qian BZ, Pollard JW. Macrophage diversity enhances tumor progression and metastasis. Cell. 2010;141:39-51. doi: 10.1016/j.cell.2010.03.014.

12. Dos Reis DC, Damasceno KA, De Campos CB, Veloso ES, Pêgas GRA, Kraemer LR,et al. Versican and tumorassociated macrophages promotes tumor progression and metastasis in canine and murine models of breast carcinoma. Frontiers in Oncology. 2019;9:577. doi: 10.3389/fonc.2019.00577.

13. Bingle $L$, Brown NJ, Lewis CE. The role of tumour-associated macrophages in tumour progression: implications for new anticancer therapies. The Journal of Pathology. 2002;196:254-265. doi: 1002/path.1027.

14. Pollard JW. Tumour-educated macrophages promote tumour progression and metastasis. Nature Reviews Cancer. 2004;4:71-78. doi: 10.1038/nrc1256.

15. Condeelis J, Pollard JW. Macrophages: obligate partners for tumor cell migration, invasion, and metastasis. 2006;124:263-266. doi: 10.1016/j.cell.2006.01.007.

16. Misdorp W, Else R, Hellmen E, Lipscomb TP. Histologic classification of mammary tumors of the dog and cat. $2^{\text {nd }}$ series, Armed Forces Institute of Pathology, 1999.

17. Cassali GD, Lavalle GE, Ferreira E, Estrela-Lima A, De Nardi AB, Ghever C, et al. Consensus for the diagnosis, prognosis and treatment of canine mammary tumors - 2013. Brazilian Journal of Veterinary Pathology. 2014; 7:153-180.

18. Karayannopoulou M, Kaldrymidou E, Constantinidis TC, Dessiris A. Histological grading and prognosis in dogs with mammary carcinomas: application of a human grading method. Journal Comparative Pathology. 2005;133:246-252. doi: 1016/j.jcpa.2005.05.003.

19. Sorenmo KU, Worley DR, Goldschmidt MH. Tumors of the mammary gland. In: Small Animal Clinical Oncology. $5^{\text {th }}$ S.J. Withrow, D.M. Vail, L.P. Rodney, (Eds.). St. Louis, Elsevier Saunders, 538-556.

20. Owen LN. TNM classification of tumors in domestic animals. World Health Organization.1980;53.

21. Leek RD, Lewis CE, Whitehouse R, Greenall M, Clarke J, Harris AL. Association of macrophage infiltration with angiogenesis and prognosis in invasive breast carcinoma. Cancer Research. 1996;56:4625-4629.

22. Takeuchi T, Hisanaga M, Nagao M, Ikeda N, Fujii F, Mukogawa T,et al. The membrane-anchored matrix metalloproteinase (MMP) regulator RECK in combination with MMP-9 serves as an informative prognostic indicator for colorectal cancer. Clinical Cancer Research. 2004;10:5572-5579. doi: 1158/1078-0432.CCR-030656. 
23. Denkert C, Loibl S, Noske A, Roller M, Muller BM, Komor M, et al. Tumor-associated lymphocytes as an independent predictor of response to neoadjuvant chemotherapy in breast cancer. Journal of Clinical Oncology. 2010;28:105-113. doi: 10.1200/JC0.2009.23.7370.

24. Seo AN, H.J. Lee, Kim EJ, Kim HJ, Jang MH, Lee HE, et al. Tumour-infiltrating CD8+ lymphocytes as an independent predictive factor for pathological complete response to primary systemic therapy in breast cancer. British Journal of Cancer. 2013;109:2705-2713. doi: 10.1038/bjc.2013.634.

25. Hellmén E, Bergstrom R, Holmberg L, Spangberg IB, Hansson K, Lindgren A. Prognostic factors in canine mammary tumors: a multivariate study of 202 consecutive cases. Veterinary Pathology. 1993; 30:20-27.doi: 1177/030098589303000103.

26. Krol M, Pawlowski KM, Majchrzak K, Gajewska M, Majewska A, Motyl T. Global gene expression profiles of canine macrophages and canine mammary cancer cells grown as a co-culture in vitro. BMC Veterinary Research. 2012; 8:1-20. doi: 10.1186/1746-6148-8-16.

27. Lewis CE, Pollard JW. Distinct role of macrophages in different tumor microenvironments. Cancer Research. 2006;66:605-612. doi: 1158/0008-5472.CAN-05-4005.

\section{Tables}

Table 1: Association between TAM counts according to histologic location and clinicopathologic featu 


\begin{tabular}{|c|c|c|c|c|c|c|c|c|c|}
\hline \multirow{2}{*}{$\begin{array}{l}\text { Clinicopathologic } \\
\text { characteristic }\end{array}$} & \multicolumn{2}{|c|}{ Intraepithelial TAM } & \multirow{2}{*}{$\begin{array}{c}P \\
\text { value }\end{array}$} & \multicolumn{2}{|c|}{ Stromal TAM } & \multirow{2}{*}{$\begin{array}{c}P \\
\text { value }\end{array}$} & \multicolumn{2}{|c|}{ Total TAM } & \multirow[t]{2}{*}{$P$ value } \\
\hline & $\begin{array}{c}\text { Low } N \\
(\%)\end{array}$ & $\begin{array}{c}\operatorname{High} N \\
(\%)\end{array}$ & & $\begin{array}{l}\text { Low } N \\
(\%)\end{array}$ & $\begin{array}{c}\text { High } N \\
(\%)\end{array}$ & & $\begin{array}{c}\text { Low } N \\
(\%)\end{array}$ & $\begin{array}{c}\operatorname{High} N \\
(\%)\end{array}$ & \\
\hline Size & & & 0.0891 & & & 0.1761 & & & $0.0017^{*}$ \\
\hline $\mathrm{T} 1(<3 \mathrm{~cm})$ & $\begin{array}{c}15 \\
(22.72)\end{array}$ & $9(13.63)$ & & $\begin{array}{c}15 \\
(22.72)\end{array}$ & $9(13.63)$ & & $\begin{array}{c}17 \\
(25.75)\end{array}$ & $\begin{array}{c}7 \\
(10.60)\end{array}$ & \\
\hline $\mathrm{T} 2(3-5 \mathrm{~cm})$ & $\begin{array}{c}8 \\
(12.12)\end{array}$ & $6(9.09)$ & & $\begin{array}{c}7 \\
(10.60)\end{array}$ & $\begin{array}{c}7 \\
(10.60)\end{array}$ & & $\begin{array}{c}8 \\
(12.12)\end{array}$ & $6(9.09)$ & \\
\hline T3 $(>5 \mathrm{~cm})$ & $\begin{array}{c}11 \\
(16.66)\end{array}$ & $\begin{array}{c}17 \\
(25.75)\end{array}$ & & $\begin{array}{c}11 \\
(16.66)\end{array}$ & $\begin{array}{c}17 \\
(25.75)\end{array}$ & & $\begin{array}{c}8 \\
(12.12)\end{array}$ & $\begin{array}{c}20 \\
(30.30)\end{array}$ & \\
\hline Node metastasis & & & 0.1491 & & & $0.0256 *$ & & & $0.0256 *$ \\
\hline $\begin{array}{l}\text { Yes } \\
\text { No }\end{array}$ & $\begin{array}{c}12 \\
(18.18) \\
22 \\
(33.33)\end{array}$ & $\begin{array}{c}17 \\
(25.75) \\
15 \\
(22.72)\end{array}$ & & $\begin{array}{c}10 \\
(15.15) \\
23 \\
(34.84)\end{array}$ & $\begin{array}{c}19 \\
(28.78) \\
14 \\
(21.21)\end{array}$ & & $\begin{array}{c}10 \\
(15.15) \\
23 \\
(34.84)\end{array}$ & $\begin{array}{c}19 \\
(28.78) \\
14 \\
(21.21)\end{array}$ & \\
\hline Distant metastasis & & & 0.1492 & & & 0.9827 & & & 0.1621 \\
\hline Yes & $\begin{array}{c}25 \\
(37.87)\end{array}$ & $\begin{array}{c}29 \\
(43.93)\end{array}$ & & $\begin{array}{c}33 \\
(50.0)\end{array}$ & $\begin{array}{c}31 \\
(46.96)\end{array}$ & & $\begin{array}{c}34 \\
(51.51)\end{array}$ & $\begin{array}{c}30 \\
(45.45)\end{array}$ & \\
\hline No & $\begin{array}{c}0 \\
(0)\end{array}$ & $2(3.03)$ & & $1(1.51)$ & $1(1.51)$ & & $\begin{array}{l}0 \\
(0)\end{array}$ & $2(3.03)$ & \\
\hline Clinical stage & & & $0.0380 *$ & & & $0.0162 *$ & & & $0.0004^{*}$ \\
\hline $\mathrm{I}$ & $\begin{array}{c}14 \\
(21.21)\end{array}$ & $7(10.60)$ & & $\begin{array}{c}14 \\
(21.21)\end{array}$ & $7(10.60)$ & & $\begin{array}{c}17 \\
(25.75)\end{array}$ & $4(6.06)$ & \\
\hline II & $2(3.03)$ & $1(1.51)$ & & $2(3.03)$ & $1(1.51)$ & & $2(3.03)$ & $1(1.51)$ & \\
\hline III & $\begin{array}{c}7 \\
(10.61)\end{array}$ & $6(9.1)$ & & $\begin{array}{c}8 \\
(12.12)\end{array}$ & $5(7.57)$ & & $5(7.57)$ & $\begin{array}{c}8 \\
(12.12)\end{array}$ & \\
\hline IV & $\begin{array}{c}10 \\
(15.15)\end{array}$ & $\begin{array}{c}17 \\
(25.75)\end{array}$ & & $\begin{array}{c}7 \\
(10.60)\end{array}$ & $\begin{array}{c}20 \\
(30.30)\end{array}$ & & $\begin{array}{c}8 \\
(12.12)\end{array}$ & $\begin{array}{c}19 \\
(28.78)\end{array}$ & \\
\hline IV & $\begin{array}{c}0 \\
(0)\end{array}$ & $2(3.03)$ & & $1(1.51)$ & $1(1.51)$ & & $\begin{array}{c}0 \\
(0)\end{array}$ & $2(3.03)$ & \\
\hline Ulceration & & & 0.8367 & & & 0.0371 & & & 0.6883 \\
\hline Yes & $\begin{array}{c}28 \\
(42.42)\end{array}$ & $\begin{array}{c}28 \\
(42.42)\end{array}$ & & $\begin{array}{c}27 \\
(40.9)\end{array}$ & $\begin{array}{c}29 \\
(43.93)\end{array}$ & & $\begin{array}{c}27 \\
(40.9)\end{array}$ & $\begin{array}{c}30 \\
(45.45)\end{array}$ & \\
\hline No & $\begin{array}{c}6 \\
(9.1)\end{array}$ & $4(6.06)$ & & $\begin{array}{c}6 \\
(9.1)\end{array}$ & $4(6.06)$ & & $4(6.06)$ & $5(7.57)$ & \\
\hline Necrosis & & & 0.5761 & & & 0.8034 & & & 0.2105 \\
\hline Yes & $\begin{array}{c}21 \\
(31.81)\end{array}$ & $\begin{array}{c}20 \\
(30.30)\end{array}$ & & $\begin{array}{c}20 \\
(30.30)\end{array}$ & $\begin{array}{c}21 \\
(31.81)\end{array}$ & & $\begin{array}{c}18 \\
(27.27)\end{array}$ & $\begin{array}{c}23 \\
(34.84)\end{array}$ & \\
\hline No & $\begin{array}{c}12 \\
(18.18)\end{array}$ & $\begin{array}{c}13 \\
(19.69)\end{array}$ & & $\begin{array}{c}14 \\
(21.21)\end{array}$ & $\begin{array}{c}11 \\
(16.66)\end{array}$ & & $\begin{array}{c}15 \\
(22.72)\end{array}$ & $\begin{array}{c}10 \\
(15.15)\end{array}$ & \\
\hline Histological grade & & & 0.6677 & & & 0.1229 & & & 0.1229 \\
\hline I & $\begin{array}{c}11 \\
(16.66)\end{array}$ & 9 (13.63) & & $\begin{array}{c}12 \\
(18.18)\end{array}$ & $8(12.12)$ & & $\begin{array}{c}12 \\
(18.18)\end{array}$ & $\begin{array}{c}8 \\
(12.12)\end{array}$ & \\
\hline II & $\begin{array}{c}19 \\
(28.78)\end{array}$ & $\begin{array}{c}14 \\
(21.21)\end{array}$ & & $\begin{array}{c}16 \\
(24.24)\end{array}$ & $\begin{array}{c}17 \\
(25.75)\end{array}$ & & $\begin{array}{c}17 \\
(25.75)\end{array}$ & $\begin{array}{c}16 \\
(24.24)\end{array}$ & \\
\hline III & $5(7.57)$ & $8(12.12)$ & & $4(6.06)$ & $9(13.63)$ & & $4(6.06)$ & $\begin{array}{c}9 \\
(13.63)\end{array}$ & \\
\hline Vascular invasion & & & $0.0235^{*}$ & & & $0.0371 *$ & & & $0.0371 *$ \\
\hline Yes & $\begin{array}{c}7 \\
(10.60)\end{array}$ & $\begin{array}{c}15 \\
(22.72)\end{array}$ & & $\begin{array}{c}7 \\
(10.60)\end{array}$ & $\begin{array}{c}15 \\
(22.72)\end{array}$ & & $\begin{array}{c}7 \\
(10.60)\end{array}$ & $\begin{array}{c}15 \\
(22.72)\end{array}$ & \\
\hline No & $\begin{array}{c}27 \\
(41.0)\end{array}$ & $\begin{array}{c}17 \\
(25.75)\end{array}$ & & $\begin{array}{c}26 \\
(39.39) \\
\end{array}$ & $\begin{array}{c}18 \\
(27.27)\end{array}$ & & $\begin{array}{c}26 \\
(39.39) \\
\end{array}$ & $\begin{array}{c}18 \\
(27.27)\end{array}$ & \\
\hline
\end{tabular}

${ }^{*} P$ value $\leq 0.05$ was considered to be statistically significant.

Table 2: Survival rates according to TAM count and histologic location in canine mammary tumors 


\begin{tabular}{lcccc}
\hline TAM count & $\boldsymbol{N}(\%)$ & Median & Mean & $\boldsymbol{P}$ value \\
\hline Intratumoral $^{\&}$ & & & & \\
\hline Low & $30(49.18)$ & Undefined & 451.56 & 0.8439 \\
High & $31(50.82)$ & 950 & 437.06 & \\
\hline Stromal & & & & \\
\hline Low & $29(47.54)$ & 613 & 482.93 & $0.0500^{*}$ \\
High & $32(52.46)$ & 950 & 409.09 & \\
\hline Total $^{\#}$ & & & & \\
Low & $22(36.07)$ & 613 & 489.5 & $0.0282^{*}$ \\
High & $39(63.93)$ & 950 & 418.6 & \\
\hline
\end{tabular}

\& Low: $\leq 61.5$; High: $>61.5$

\$ Low: $\leq 57.5$; High: $>57.5$

\# Low: $\leq 149 ;$ High: $>149$.

* $P$ value $\leq 0.05$ was considered to be statistically significant.

\section{Figures}




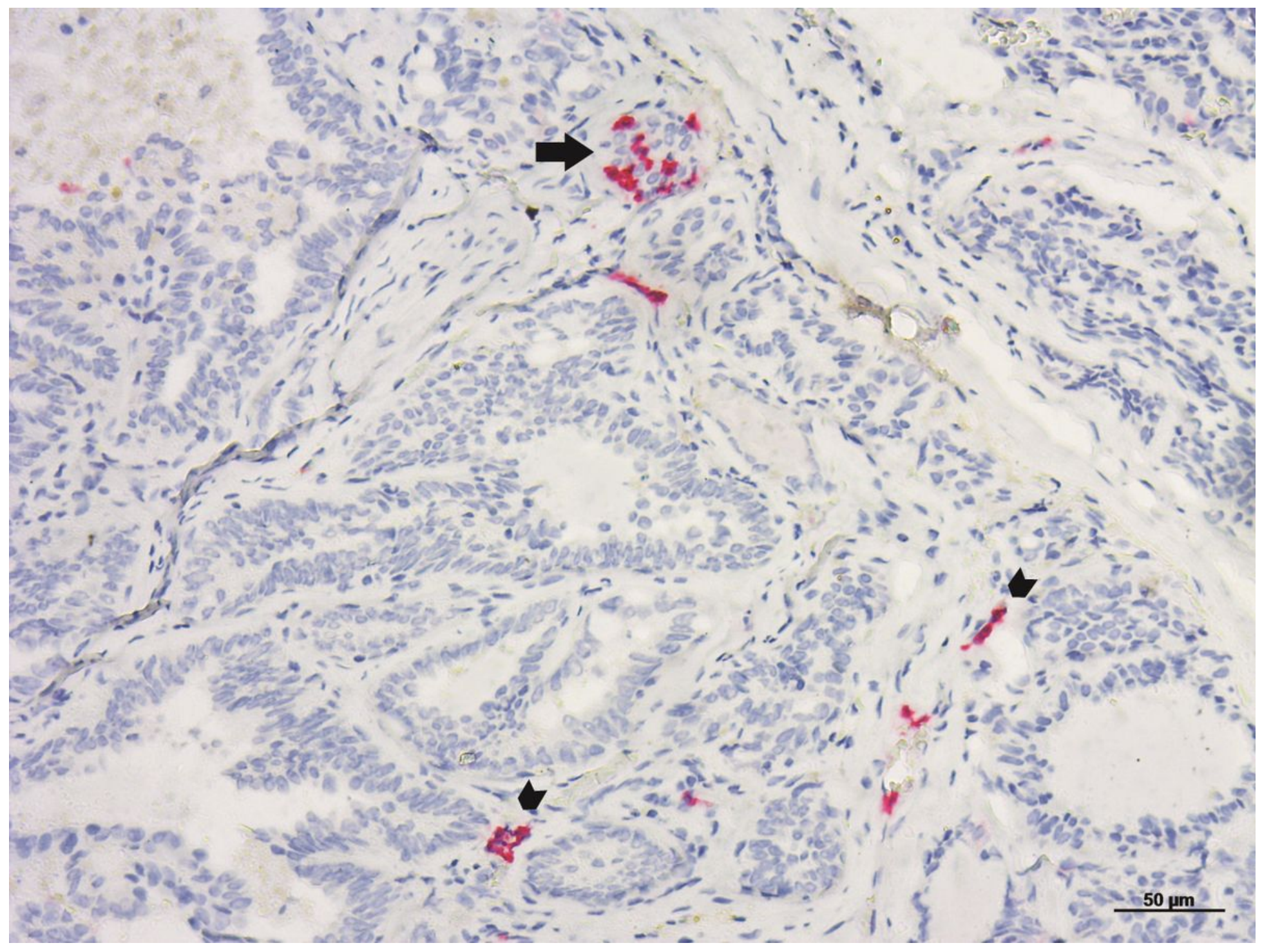

Figure 1

Microscopic view of a canine mammary carcinoma with tumor-associated macrophages can be observed as intratumoral (arrow) and stromal TAM (arrowhead). Permanent red immunohistochemistry, Harris hematoxylin counterstain (bar $=50 \mu \mathrm{m})$.
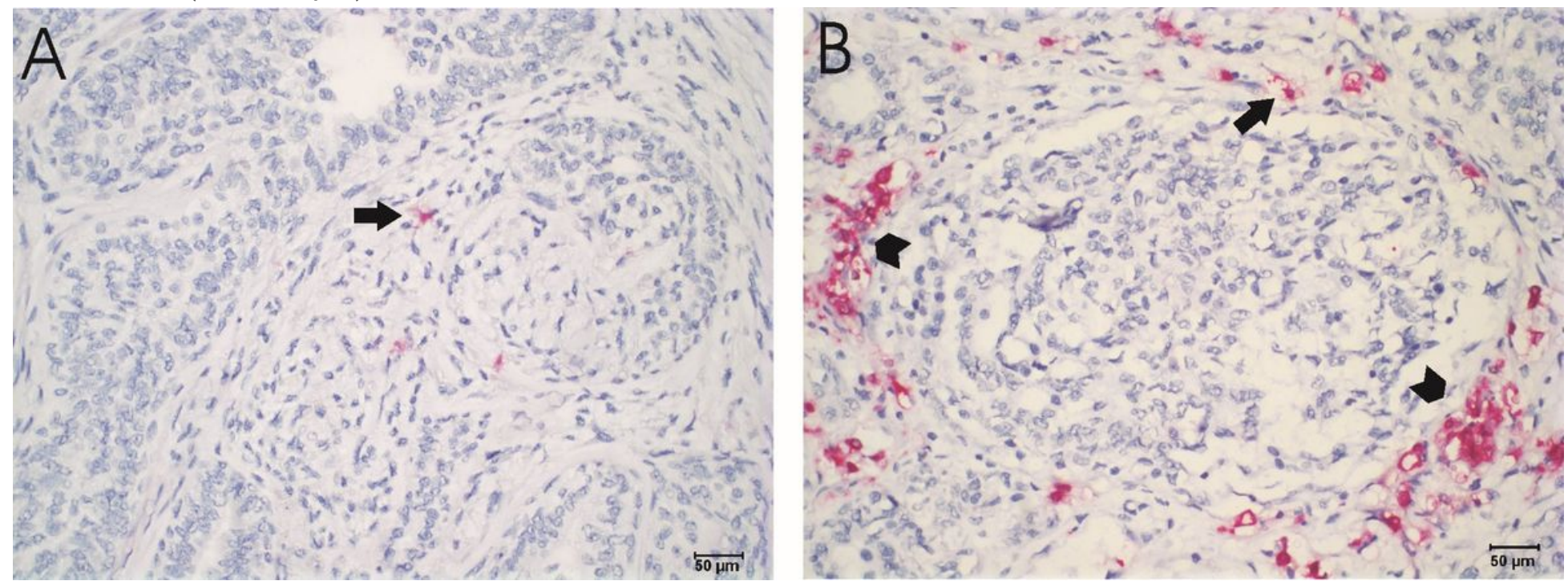


\section{Figure 2}

Canine mammary carcinomas with low (A) and high (B) TAM infiltration. Arrows indicate single macrophages stained (red) at the stroma of the tumor front. Arrowheads indicate clustered macrophages forming densely packed groups at the stroma of the tumor front. Permanent red immunohistochemistry. Harris hematoxylin counterstain (x20 objective).
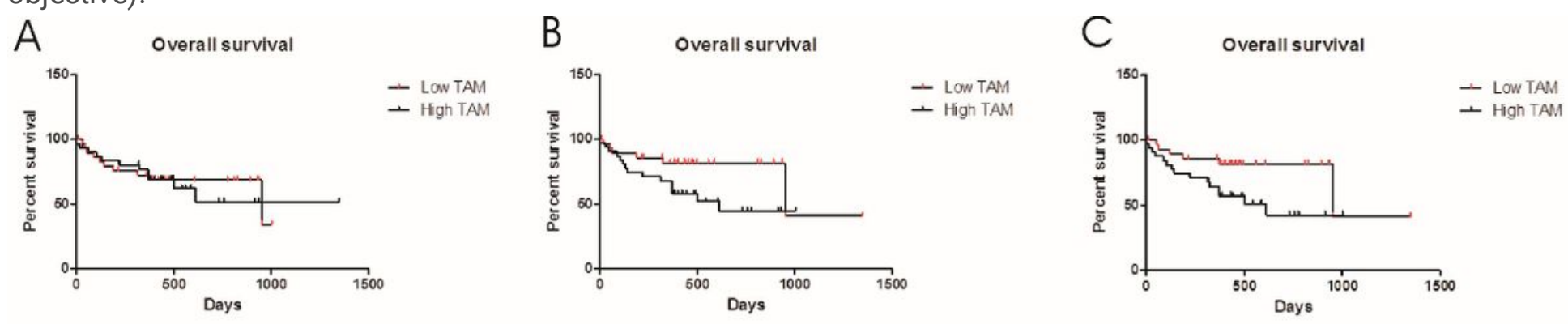

\section{Figure 3}

Kaplan-Meier survival analysis for OS based on low and high TAM counts in dogs with mammary carcinomas. A) Intratumoral TAM (log rank test, $P=0.8439$ ); B) Stromal TAM (log rank test, $P=0.0500)$; C) Total TAM (log rank test, $P=0.0282)$. 